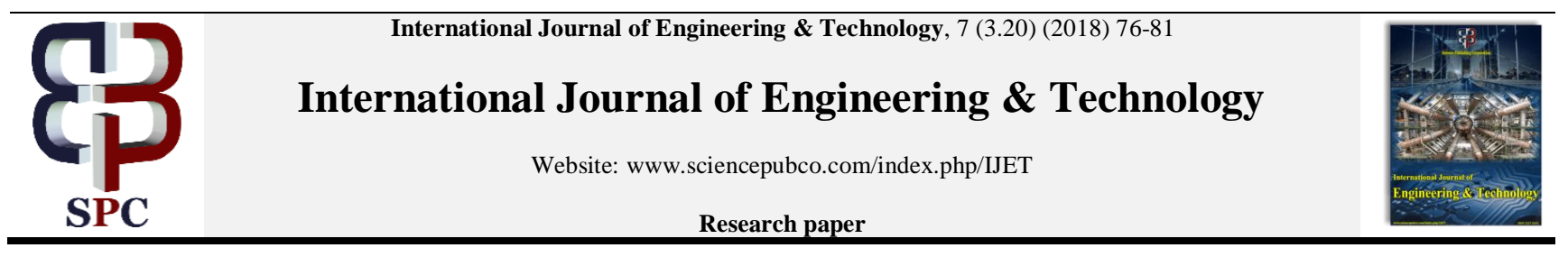

\title{
A Systematic Literature Review on Risk Factors in Software Development Outsourcing
}

\author{
Alawiyah Abd Wahab and Teh Piak San \\ ${ }^{a}$ School of Computing, College of Arts and Sciences, UUM, 06010, Sintok, Kedah, Malaysia
}

\begin{abstract}
Software development outsourcing has become a prevalent practice in the software industry. Organizations in both public and private sectors are adopting software development outsourcing in order to achieve lower cost and to access to skilled labour. However, it is widely recognized that outsourced software development projects involve risks and sometimes leads to undesirable consequences. Existing research in the software engineering and related areas have identified several risks in the software development outsourcing projects such as lack of communication and technical skills. The aim of this paper is to examine the literature on outsourced software development in order to identify some risks that could occur during the pre-contract, contract and post-contract phases of the outsourcing life cycle. It is anticipated that by understanding these risks, project managers could better manage them and subsequently increase the possibility of the success of outsourcing project. A systematic literature review of studies on software development outsourcing published in year 2005 to year 2015 was conducted. Of 41 studies consulted, 18 were concerned with outsourcing software development risk factors. The top three risk factors identified are lack of required technical skills and competencies (61\%), lack of communication (44\%) and poorly articulated requirements (44\%).
\end{abstract}

Keywords: Software development outsourcing, risk, risk factors, systematic literature review

\section{Introduction}

Software development outsourcing is a very important practice in any organization both in the public and private sectors. Recently it has become part of organizations' overall business strategy to gain global competitiveness. Software development outsourcing can be referred to as providing services such as "managing data center operations, software and hardware support and maintenance, network services and other services in software development activities" by other third party companies or vendors [1]. The demands of software development outsourcing in organization are growing rapidly due to the associated benefits of outsourcing and limitation of organizations. Involvement of users and practitioners is an effective way to better manage and control over system development risks during project implementation and development. Several possible reasons that lead organizations to outsource software development projects include improving organization focus, increasing feasibility, improving software quality, facilitating access to technology, reducing the risk of obsolescence and reducing and controlling operating costs [2].

Furthermore, several potential benefits of software development outsourcing have been recognized such as reduce recruitment, operation and development costs, increase operational efficiency, and access to global resource pools [3]. Although there are significant risks involved in outsourcing if it fails, there are still many organizations outsource their software development projects in the belief that it will lower their operational costs.
The software development outsource has become risky in various situations. The risk factors of software development outsourcing can be classified based on the three phases of the outsourcing life cycle; pre-contract, contract and post contract. The pre-contract phase of outsourcing can be defined as the evaluation phase or early stage of the outsourcing process where it emphasizes on outsourcing strategy and evaluation of vendors [4]. The contract phase occurs during implementation of software development through the organization structure and internal process of vendor. The post-contract phase is concerned about the assessment of quality of the software development outsourcing project after contract expiration such as outsourcing contract and vendor's quality of service.

\section{Literature Review}

A number of researchers $[5,6,7,8,9]$ have explored the vendors perspectives of risk associated with outsourced software development. For example, [5] conducted a Delphi study to identify the risk factors and the main goals of offshore-outsourced software development in Bangladesh. The study identified and ranked ten risk factors from the developing country context. Lack of involvement and effective communication with the client were found to be the top risk factors. [6] conducted a content analysis and reported 22 risks pertaining to client's end, 20 risks pertaining to vendor's end and six risks pertaining to inter-firm relationship. [7] compared the perspective of vendor IT project managers and existing survey of in-house IT project managers. Although the 
study found the risk factors identified by vendor IT project managers were similar to those identified in the previous survey of in-house IT project managers, some risks are specific to vendor organization such as risks from vendor's competitors and risks to the vendor's reputation from the involvement in the outsourcing projects.

While some researchers focused on vendor's perspective, others contributed their insights into risk factors of software development outsourcing from the clients' perspectives [2, 10, 11, 12, 13]. For example [10] utilized the Delphi method to rank conventional risk factors identified in earlier research. The study sought the input from 15 experienced project managers involved in offshore project. The top ten risk factors identified include lack of top management commitment, miscommunicated project requirement, lack of communication, failure to manage end-user expectations and inadequate user involvement. [11] used a case study approach to examine an outsourced strategic IT development project to identify the risk factors leading to its failure. They found risk factors that related to contract, requirements, project complexity, planning and control execution and team.

The previous paragraphs have shown that researchers have investigated risks of outsourced software development from both

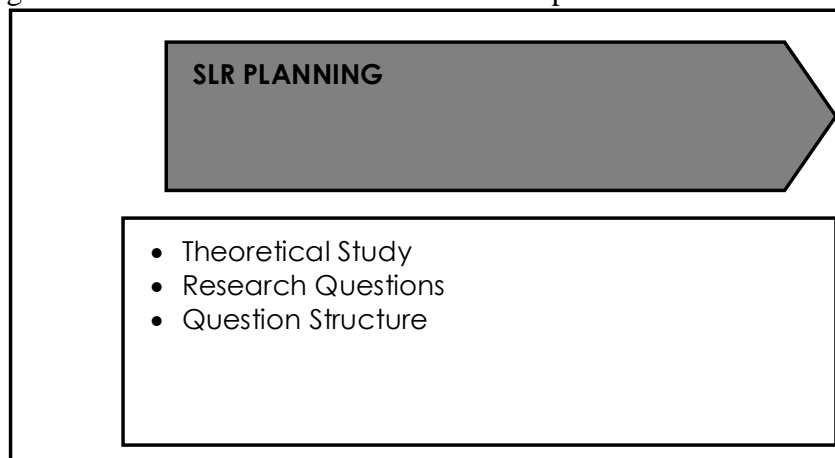

client and vendors perspectives. However, little attention has been made to map between the identified risk factors and its associated phases of the outsourcing life cycle. By having knowledge of risk factors associated with each phases of the outsourcing life cycle, project managers could make an informed decision before embarking on an outsourcing project. Hence, in this paper, a systematic literature review is conducted to examine the risk factors in the software development outsourcing and map the risks onto each phases of the life cycle.

\section{Methodology}

This study has been undertaken as a standard systematic literature review (SLR) approach by performing all processes such as planning a review, conducting the review and reporting the review based on the guidelines from engineering researchers [14]. SLR is defined as a systematic way of identifying, evaluating and analyzing published studies in order to investigate a specific research question [15]. Figure 1 shows the overall process of SLR for conducting this study.

Figure 1 The SLR process

\subsection{Planning the Review}

The steps and activities of SLR are documented below:

i. Theoretical study

The purpose of the theoretical study is to understand the associated concept of risk factors in software development outsourcing. All information associated to risk factors of software development outsourcing are collected and gathered in order to analyze and identify the risk factors. ii. Research question

The research question for this study is: What are the risk factors of software development outsourcing in the three phases of outsourcing life cycle that organizations have to be aware of before embarking on any outsourcing project?

iii. Question structure

In this stage, the information is obtained from conference proceeding, online journals and books, unpublished theses and other related sources from websites.

The population, intervention, comparison, outcomes, and context (PICOC) structure of questions are shown in

Table 1 .

Table 1 Summary of PICOC

\begin{tabular}{|c|c|}
\hline Structure & Measures \\
\hline Population & Software outsourcing vendors and clients \\
\hline Intervention & Risk factors \\
\hline Comparison & None \\
\hline Outcomes & Risk factors in the three phases of outsourcing life cycle \\
\hline Context & Case study, systematic literature review, exploratory study \\
\hline
\end{tabular}




\subsection{Conducting the Review}

i. Data Collection

In this stage, all published papers related to the research question were manually searched through the Internet and electronic online databases from year 2005 to 2015. The sources of journals and conference proceedings are shown in Table 2 below.

Table 2 Sources of journals and proceedings

\begin{tabular}{|l|c|}
\hline Sources & URLs \\
\hline \multirow{2}{*}{ Online Database } & ACM digital library \\
\cline { 2 - 2 } & Science Direct \\
\hline Online search engine & IEEE \\
\hline Library repository & Google Scholar \\
\hline
\end{tabular}

\section{ii. Search terms}

The search terms being used includes "outsourcing", "software development outsourcing", "risk", "risk management", "risk factors" and "systematic literature review". Different kinds of search terms were being used to retrieve articles from online database, search engine and repository library. Each search terms has interaction/relevant to each others. Besides, all research papers need to be identified and scanned through in order to retrieve the right papers.

iii. Selection of papers

By using the search strategies as presented above, a massive amount of the articles listed in the databases were found. The research topic area has been selected based on appropriate previous studies and published from year 2005 to 2015. Articles were included if they were:-

- Reported in English language only.

- Full conference papers based on the topic selection and search terms.

- Studies that described the risk factors in software development outsourcing.

- Studies that described the risk factors in software development outsourcing in every phases of the outsourcing life cycle.

However, those that were not related to the topic have been excluded, which were:-

- Studies that were not related to the research questions.

- Studies that did not describe about outsourcing risk factors in software development outsource iv. Data extraction

In this stage, each article was reviewed in order to understand the subject where the authors classified and formed a general structure of each article. By reviewing the article, the following information was collected in order to answer research question:-

- Categorization of risks: Risks can be defined in different term in various areas. In this study, we only focused on outsourcing risk in software development outsourcing.

- Categorization of outsourcing: Outsourcing can be differentiated in software and hardware. For this study, we only focused on software development outsourcing. Other outsourcing projects that did not concern software development were excluded such as infrastructure management and service outsourcing.

- Categorization of risk factors in software development outsource: The risk factors were the key concern in this study for software development outsourcing. These risk factors were mapped onto the three phases of the outsourcing life cycle which were pre-contract, contract and post-contract.

- The data collection forms included all publication information such as title, authors, journal and publication details (risk Factors in software development outsourcing).

- The number of papers identified from 2005- 2015 are shown in Table 3 below.

Table 3 The number of papers selected

\begin{tabular}{|l|l|c|c|}
\hline \multicolumn{1}{|c|}{ ID } & \multicolumn{1}{|c|}{ Source } & Total results found & Final selection \\
\hline R1 & ACM Digital Library & 5 & 1 \\
\hline R2 & Science Direct & 5 & 1 \\
\hline R3 & IEEE & 16 & 5 \\
\hline R4 & Google Scholar & 15 & 11 \\
\hline
\end{tabular}

v. Quality assessment

The final selection of the primary studies was performed by assessing their quality. The quality assessment was done in parallel with the data extraction stage. The quality of each paper was scored based on the following quality checklist as shown in
Table 4. The total score for each article is calculated by adding the score of each quality checklist. As a result, the range of the total score for each article is between 0 and 4 .

Table 4 Quality checklist (adapted from [16])

\begin{tabular}{|c|c|c|}
\hline No & Criteria & Score \\
\hline QC1 & Was the aim of the study clearly stated? & $\begin{array}{c}\text { Yes }(1) \\
\text { Partly }(0.5) \\
\text { No }(0)\end{array}$ \\
\hline
\end{tabular}




\begin{tabular}{|c|c|c|}
\hline QC2 & Were the data collection process carried out well? & $\begin{array}{c}\text { Yes (1) } \\
\text { Partly }(0.5) \\
\text { No }(0)\end{array}$ \\
\hline QC3 & Was the data analysis sufficiently rigorous? & $\begin{array}{c}\text { Yes (1) } \\
\text { Partly }(0.5) \\
\text { No }(0)\end{array}$ \\
\hline QC4 & Is there a clear statement of findings? & $\begin{array}{c}\text { Yes (1) } \\
\text { Partly (0.5) } \\
\text { No (0) }\end{array}$ \\
\hline
\end{tabular}

\section{Results and Discussion}

This section presents the findings related to our research question based on the SLR process. Based on the quality assessment stage, $10(55 \%)$ articles are categorized as having very good quality and five $(28 \%)$ articles are considered as having good quality. The rest of the papers $(17 \%)$ are of fair quality. Table 5 shows the summarized results of the quality assessment stage.

\begin{tabular}{|l|l|c|c|c|c|}
\hline \multicolumn{1}{|c|}{ Scale } & $\begin{array}{l}\text { Poor } \\
(\mathbf{1 - 1 . 9 9})\end{array}$ & $\begin{array}{c}\text { Fair } \\
(\mathbf{2 - 2 . 9 9 )}\end{array}$ & $\begin{array}{c}\text { Good } \\
(\mathbf{3 - 3 . 9 9})\end{array}$ & $\begin{array}{c}\text { V. Good } \\
(\mathbf{4})\end{array}$ \\
\hline No & 0 & 3 & 5 & 10 & 18 \\
\hline$\%$ & 0 & 17 & 28 & 55 & 100 \\
\hline
\end{tabular}

Table 6 shows the summary of the risk factors identified from four main sources of the 18 papers included in the data analysis. Overall, we identified a total of 15 major risk factors. The process of categorizing the risks was quite difficult because the respective authors used various terms to represent one risk factor. For example, "distinctive capability in IT", "expertise in IT operation". Therefore, we clustered the risks based on their meanings where we think they best matched. However, other researchers might use different approach.

Table $6 \mathrm{Ri}$ sk factors in software development outsourcing

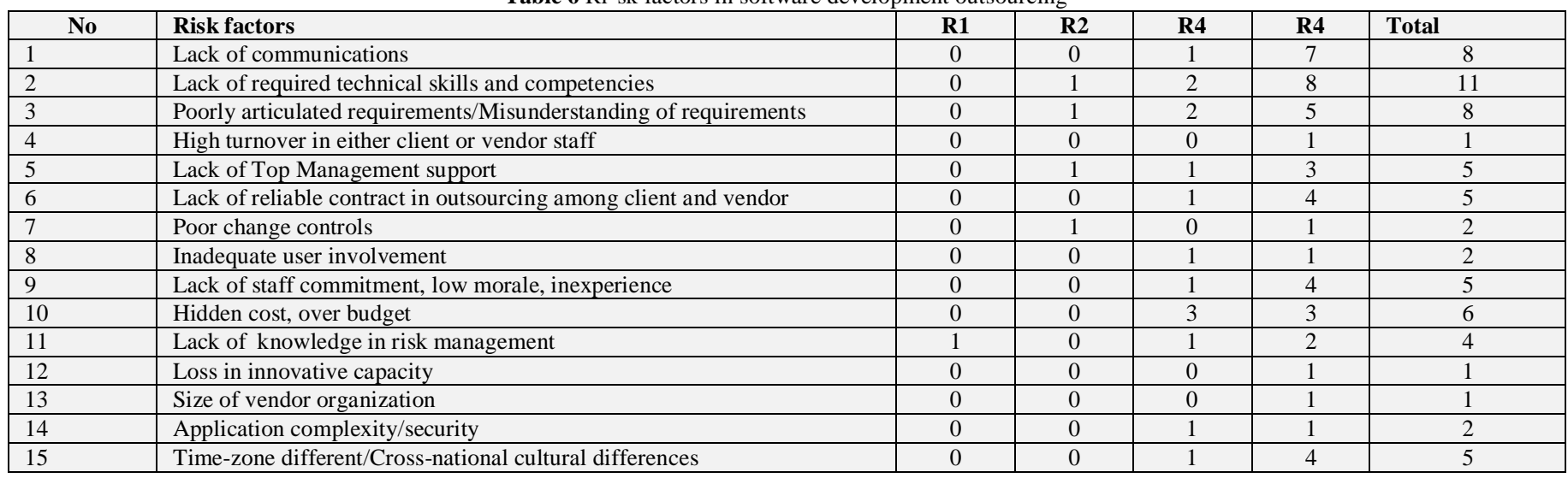

Figure 2 illustrates the frequency of an item being identified as a risk in the selected papers. The most frequently risk factors being cited in the selected papers is "lack of required technical skills and competencies" with $17 \%$ frequencies.

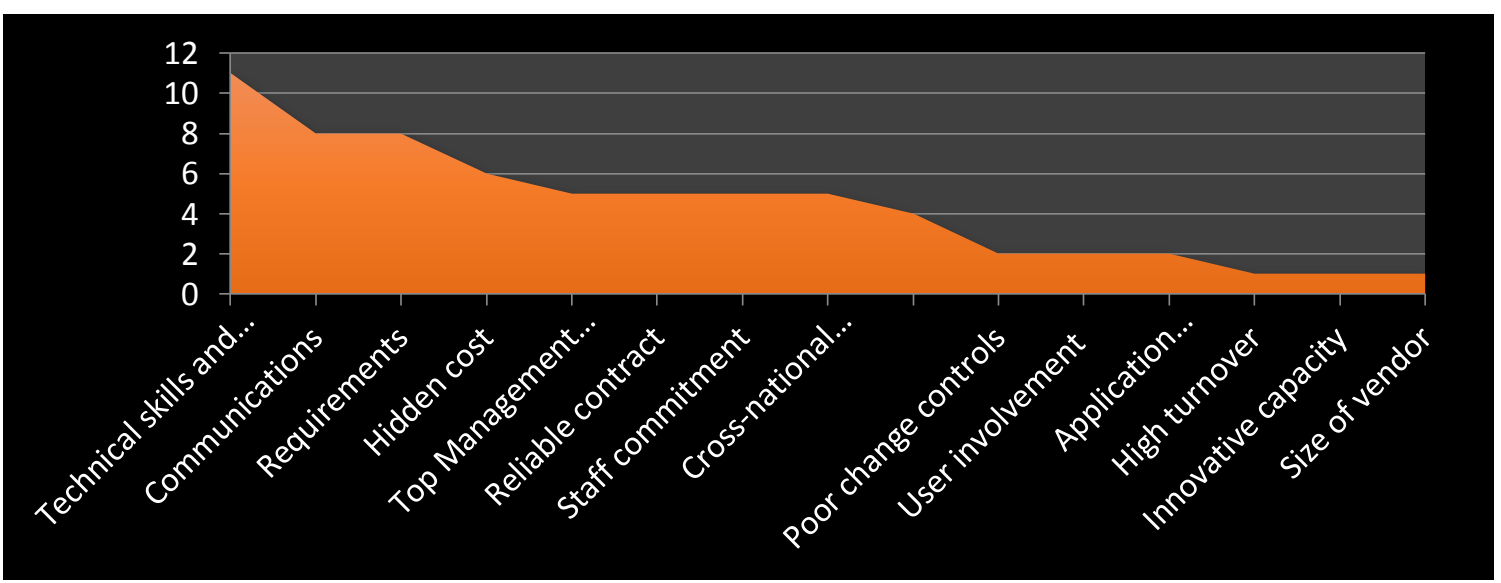

Figure 2 The frequency of the risk factors 
Three risk factors received less attention within the reviewed papers with only $1 \%$ frequency including "loss in innovative capacity", "size of vendor organization", and "high turnover in either client or vendor staff". This finding suggests that the technical skills and competencies are important in the software development outsourcing. In their studies of critical success factors, [17] also found vendors' technical competencies as one of the factors affecting the success of an IT outsourcing partnership. The identified risk factors were then mapped onto the three phases of the outsourcing life cycle. As discussed in the introduction section, each phase has distinct activities. Therefore, the risk factors were mapped to each phase based on the activity of each phase. For example, in the pre-contract phase client organization will conduct vendors' capability evaluation. The strengths and capabilities of the vendor organization will have remarkable impact on the success of an outsourcing project. Therefore, we consider two risks, size of vendor organization and lack of technical skills and competencies as risks that are associated with vendors' capabilities in the pre-contract phase.

\subsection{The Pre-Contract Phase}

The first risk factor concerns with the lack of communication. Communication is important for both client and vendor to understand the requirements of software development project. Lack of communication may cause misunderstanding of the client's requirements on the outsourcing project. Poorly written requirements will lead to project failure if the software developed did not meet the client's expectation. The second risk factor is related to the internal skill sets of both client and vendor staff. Furthermore, the size of vendor organization should also be considered at the pre-contract phase. The organization should identify the ability or capabilities of vendor organization in order to ensure that they could handle the project. The top management support should also be considered at this stage. Without the support of the top management, a project could fail due to insufficient resources such as manpower, budget and resources.

\subsection{The Contract Phase}

Of 15 risk factors, nine were mapped into the contract phase. In this phase, communication was important to verify the project requirements. In addition to communication, user involvement was also important. The involvement of users could help educate them about the risks and challenges of software development. Furthermore, the technical skills were required in both the organization and the vendor sides. For example, the staff in both sides should have related skills to manage the outsourcing project. If the project is an offshore outsourcing, different time zone between both countries and cultural difference could also be a risk factor that should be considered during contracting phase.

\subsection{The Post-Contract Phase}

After software development outsourcing project ended, the organization was required to be aware of the risk factors during the post-contract phase. In this study, only three risk factors were mapped into the pre-contract phase. The hidden cost and budget deficits always occur after outsourcing due to poor control over the expenses when planning for outsourcing. Table 7 shows the summary of the risk factors in each phase of the outsourcing life cycle.

Table 7 Risk factors in the three phases of outsourcing life cycle

\begin{tabular}{|l|l|}
\hline \multicolumn{1}{|c|}{ Phase } & \\
\hline Pre-contract & - Lack of communication \\
& - Poorly articulated requirement \\
& - Lack of top management support \\
\hline Contract & - Lack of vendor organization \\
& - Inadequate user involvement \\
& - Lack of technical skills and competencies \\
& - Lack of communication \\
& - Ligh turnover in client and vendor staff \\
& - Time-zone different \\
& - Application complexity \\
\hline Post-contract & - Loss in innovation capacity \\
& - Lack of reliable contract \\
& - Pidden cost \\
\hline
\end{tabular}

\section{Conclusion}

This paper has described the SLR process undertaken to study the risk factors in the software development outsourcing. A total of 15 major risk factors were identified and mapped into the three phases of the outsourcing life cycle. The risk factors include "lack of required technical skills and competence", "high turnover in either client or vendor", "loss in innovative capacity", "size of vendor organization", "lack of communication", "Poorly articulated requirement/Misunderstanding of requirement", "lack of top management support", "size of vendor organization" and "lack of technical skills and competencies". The results from this SLR can be used by project managers to make an informed decision before embarking on any software development project. Further work includes using the results of this SLR as a basis for conducting a survey to assess the perception of practitioners in the software industry.

The life cycle-based classification of risks in software development outsourcing has been adopted in this paper. This classification is useful to project managers as it allows them to address specific software development risks that relate to the current phase of the outsourcing project. It is essential that risks are identified and 
prioritized at the pre-contract stage. Failure to manage risks stem from inadequate risk identification early in the life cycle could lead to unsuccessful outsourcing project.

Based on the findings, some risks may occur in several different life cycle phases. A closer look at these risks suggests that they originate from common sources for example, clients' or vendors'. By being aware of the sources of these risks, a project manager may be able to manage risks that affect several lice cycle phases more effectively.

\section{Acknowledgement}

This research is fully supported by RACE grant. The authors fully acknowledged the Ministry of Higher Education (MOHE) and Universiti Utara Malaysia for the approved fund which makes this important research viable and effective.

\section{References}

[1] R. Kishore, H. R. Rao, K. Nam, S. Rajagopalan, and A. Chaudhury, "A relationship perspective on IT outsourcing," Communications of the ACM, vol. 46, pp. 86-92, 2003.

[2] R. Gonzalez, J. Gasco, and J. Llopis, "Information systems outsourcing reasons and risks: a new assessment," Industrial Management \& Data Systems, vol. 110, pp. 284-303, 2010.

[3] S. Betz and J. Mäkiö, "Applying the OUTSHORE approach for risk minimisation in offshore outsourcing of Software Development projects," presented at the Multikonferenz Wirtschaftsinformatik, 2008.

[4] L. Rantakari, "Governance in business process outsourcing: case study on call center outsourcing," 2010.

[5] S. Islam, M. M. A. Joarder, and S. H. Houmb, "Goal and risk factors in offshore outsourced software development from vendor's viewpoint," in Global Software Engineering, 2009. ICGSE 2009. Fourth IEEE International Conference on, 2009, pp. 347-352.

[6] A. T. Chatfield and P. Wanninayaka, " IT offshoring risks and governance capabilities," presented at the The 41st Hawaii International Conference on System Sciences, 2008.

[7] H. Taylor, "The Move to Outsourced IT Projects: Key Risks from the Provider Perspective," presented at the The 2005 ACM SIGMIS CPR Conference on Computer Personnel Research, 2005.

[8] M. D. Aundhe and S. K. Mathew, "Risks in offshore IT outsourcing: A service provider perspective," European Management Journal, vol. 27, pp. 418-428, 2009.

[9] A. W. Khan and S. U. Khan, "Offshore software development outsourcing contract from vendors' perspective: a systematic literature review protocol'," IOSR J. Comput. Eng.(IOSRJCE), vol. 2, pp. 26-37, 2012.

[10] R. T. Nakatsu and C. L. Iacovou, "A comparative study of important risk factors involved in offshore and domestic outsourcing of software development projects: A two-panel Delphi study," Information \& Management, vol. 46, pp. 57-68, 2009.

[11] J. M. Verner and L. M. Abdullah, "Exploratory case study research: Outsourced project failure," Information and Software Technology, vol. 54, pp. 866-886, 2012.

[12] R. Gonzalez, J. Gasco, and J. Llopis, "Information systems outsourcing risks: a study of large firms," Industrial management \& Data systems, vol. 105, pp. 45-62, 2005.

[13] J. W. Rottman and M. C. Lacity, "A US Client's learning from outsourcing IT work offshore," Information Systems Frontiers, vol. 10, pp. 259-275, 2008

[14] B. Kitchenham, "Procedures for performing systematic reviews," Keele, UK, Keele University, vol. 33, pp. 1-26, 2004

[15] M. Staples and M. Niazi, "Experiences using systematic review guidelines," Journal of Systems and Software, vol. 80, pp. 1425-1437, 2007.

[16] T. Dybå and T. Dingsøyr, "Empirical studies of agile software development: A systematic review," Information and software technology, vol. 50, pp. 833-859, 2008
M. Alexandrova, "IT outsourcing partnerships: Empirical research on key success factors in Bulgarian organizations," Management: Journal of Contemporary Management Issues, vol. 17, pp. 31-50, 2012.

\section{Appendix}

List of 18 selected papers in the SLR:

[1] B. Bahli and S. Rivard, "Validating measures of information technology outsourcing risk factors," Omega, vol. 33, pp. 175-187, 2005.

[2] R. T. Nakatsu and C. L. Iacovou, "A comparative study of important risk factors involved in offshore and domestic outsourcing of software development projects: A two-panel Delphi study," Information \& Management, vol. 46, pp. 57-68, 2009

[3] R. Gonzalez, J. Gasco, and J. Llopis, "Information systems outsourcing risks: a study of large firms," Industrial management \& Data systems, vol. 105, pp. 45-62, 2005.

[4] N. H. Arshad, A. Mohamed, and Z. Matnor, "Risk factors in software development projects," presented at the Proceedings of the 6th WSEAS Int. Conf. on Software Engineering, Parallel and Distributed Systems, 2007.

[5] A. W. Khan and S. U. Khan, "Offshore software development outsourcing contract from vendors' perspective: a systematic literature review protocol'," IOSR J. Comput. Eng.(IOSRJCE), vol. 2, pp. 26-37, 2012.

[6] T. Philip and E. Wende, "Early Warning Signs of Failure in Offshore Outsourced Software Project-An Indo-German Case Study," presented at the Fifth Global Sourcing Workshop, Courchevel, 2011.

[7] F. de Sá-Soares, D. Soares, and J. Arnaud, "Towards a Theory of Information Systems Outsourcing Risk," Procedia Technology, vol. 16, pp. 623-637, 2014.

[8] L. M. Abdullah and J. M. Verner, "Risk framework for outsourced strategic IT system development from the client perspective," in Software Metrics European Forum, Milan, Italy, 2008, pp. 1-12.

[9] W. E. Sullivan and O. K. Ngwenyama, "How are public sector organizations managing IS outsourcing risks? An analysis of outsourcing guidelines from three jurisdictions," Journal of Computer Information Systems, vol. 45, pp. 73-87, 2005.

[10] B. Aubert, M. Patry, and S. Rivard, "Assessing the risk of IT outsourcing," in System Sciences, 1998., Proceedings of the ThirtyFirst Hawaii International Conference on, 1998, pp. 685-692.

[11] S. Islam, S. H. Houmb, D. Mendez-Fernandez, and M. A. Joarder, "Offshore-outsourced software development risk management model," in Computers and Information Technology, 2009. ICCIT'09. 12th International Conference on, 2009, pp. 514-519.

[12] J. H. Yahaya, N. F. Hamzah, and A. Deraman, "Evaluating vendor's performance in outsource software development risks using analytic hierarchy process technique," in Software Engineering Conference (MySEC), 2014 8th Malaysian, 2014, pp. 61-66.

[13] D. Tan, "Factors related to IT outsourcing result," Journal of Outscoring and Organizational Information Management, vol. 1, pp. 18-26, 2009.

[14] K. Siakas and E. Siakas, "Outsourcing: achieving high quality software," in SOFTWARE QUALITY MANAGEMENTINTERNATIONAL CONFERENCE-, 2006, p. 143.

[15] S. Gholami, "Critical risk factors in outsourced support projects of IT," Journal of Management Research, vol. 4, 2011.

[16] S.-T. Lu and S.-H. Yu, "Risk factors assessment for software development project based on fuzzy decision making," International Journal of Information and Electronics Engineering, vol. 2, pp. 596600, 2012.

[17] D. Ruan, "Choquet integral based aggregation approach to software development risk assessment," Information Sciences, vol. 180, pp. 441$451,2010$.

[18] R. Aron, E. K. Clemons, and S. Reddi, "Just right outsourcing: understanding and managing risk," Journal of Management Information Systems, vol. 22, pp. 37-55, 2005. 